\title{
On the errors involved in ice-thickness estimates I: ground-penetrating radar measurement errors - ERRATUM
}

\section{Erratum}

Cite this article: Lapazaran $\mathrm{JJ}$, Otero J, Martín-Español A, Navarro FJ (2021). On the errors involved in ice-thickness estimates I: ground-penetrating radar measurement errors - ERRATUM. Journal of Glaciology 67(263), 576. https://doi.org/10.1017/jog.2021.23

First published online: 11 March 2021

\section{J.J. Lapazaran, J. Otero, A. Martín-Español and F.J. Navarro}

https://doi.org/10.1017/jog.2016.93, Published by Cambridge University Press: 30 September 2016

In Figure 4, the $x$-axis label erroneously reads "Ice-thickness error, $\varepsilon_{x y}(\mathrm{~m})$ ", while it should read "Error in horizontal positioning, $\varepsilon_{x y}(\mathrm{~m})$ ". A corrected version of Figure 4 is supplied below.

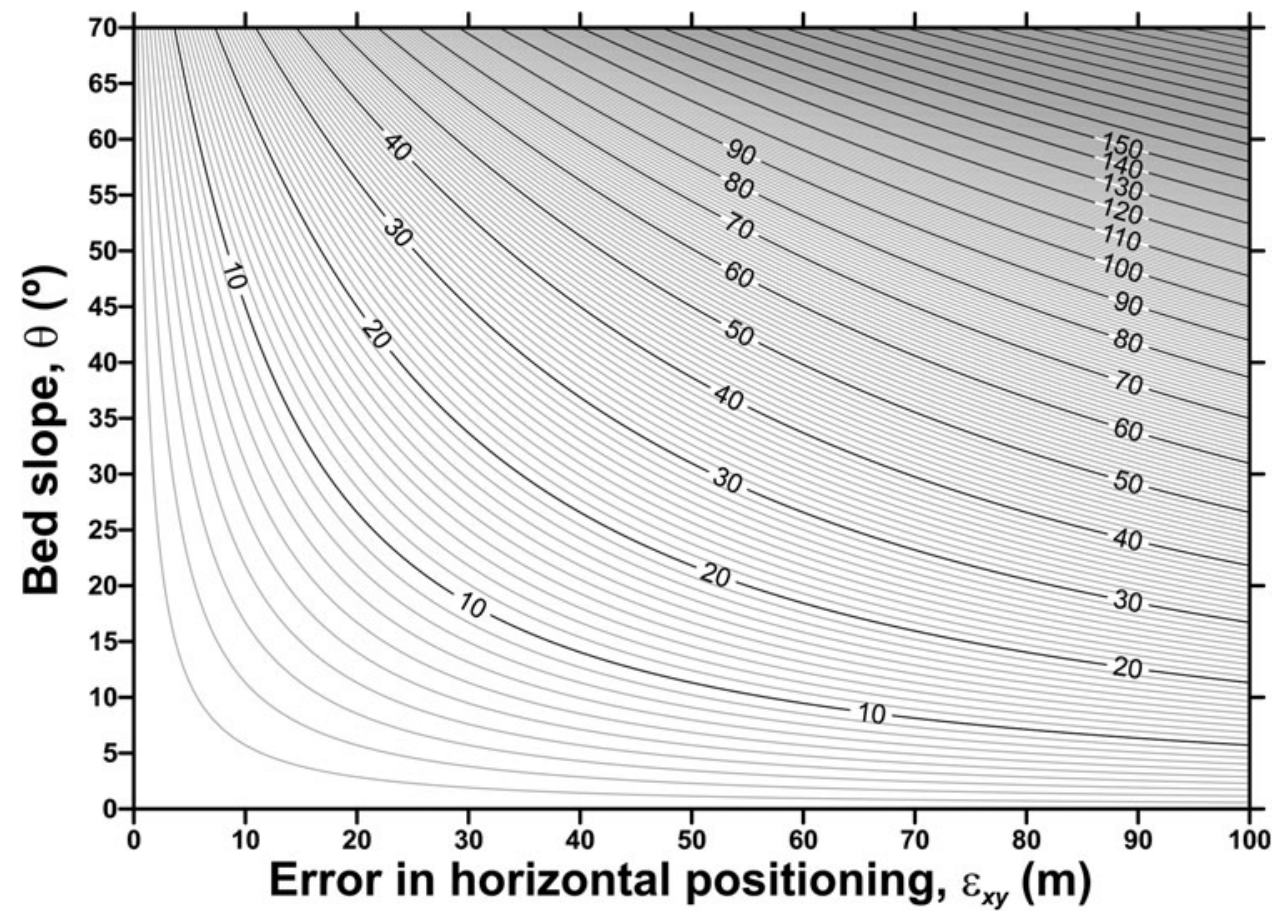

Fig. 4. Error in ice thickness, $\varepsilon_{\mathrm{Hxy}}(\mathrm{m})$, for a given error in position, $\varepsilon_{\mathrm{xy}}$, and a given bed slope with angle $\theta$.

\section{Reference}

Lapazaran JJ, Otero J, Martín-Español A and Navarro FJ (2016) On the errors involved in ice-thickness estimates I: ground-penetrating radar measurement errors. Journal of Glaciology 62(236), 1008-1020 (doi:10.1017/jog.2016.93) (c) The Author(s), 2021. This is an Open Access article, distributed under the terms of the Creative Commons Attribution licence (http:// creativecommons.org/licenses/by/4.0/), which permits unrestricted re-use, distribution, and reproduction in any medium, provided the original work is properly cited. 